\title{
Study of The Economic Dispatch Problem on IEEE 30-Bus System using Whale Optimization Algorithm Haider J.Touma
}

\author{
University of Technology,Iraq.
}

\section{Email:haidertomah@yahoo.com}

Abstract -This work presents one of the latest meta heuristic optimization approaches named Whale Optimization Algorithm method as a new strategy to solve the Economic Dispatch problem. The execution of the utilized algorithm is verified using standard test system of IEEE 30-Bus. The proposed algorithm delivered optimum or close optimum solutions. The achieved results in this study using the above mentioned Algorithm have been compared with the obtained results using other intelligent methods such as Particle Swarm Optimization, Ant Colony optimization and Genetic Algorithm. The comparison explained the obtained results in this study are close to these obtained using the above revealed approaches.

Key words-Whale Optimization Algorithm (WOA), Economic Dispatch (ED), Particle Swarm Optimization (PSO), Ant Colony Optimization (ACO), Genetic Algorithm (GA).

\section{Introduction}

The conventional economic dispatch is one of the most essential issues in the management of power system operation. The main task for economic operation of power plants is scheduling the generating units to achieve minimum generation cost for the power utilities that means low-cost electricity which makes these utilities are more competitive in the electricity market. This target is still difficult because the produced electric energy cannot be stored as other economic products as well as the commercial transportation to the consumers includes transmission and distribution systems which required accurate estimation for the generation and services costs. The heuristic optimization techniques have been the back bone in the solving of most economic engineering challenges, thus this research has depended on the new efficient method as attempt to find the optimum solutions.

\section{Problem Formulation}

Undertaking a minimum cost operation has been performed by economic allocation of load between the different generating units, thus the operating cost of the unit must be expressed as a function of the power output. The mathematical form for the fuel-cost function in the most studies is a second order curve as given in equation (1).

$\mathrm{FC}_{\mathrm{i}}=\mathrm{a}_{\mathrm{i}} \mathrm{P}_{\mathrm{i}}^{2}+\mathrm{b}_{\mathrm{i}} \mathrm{P}_{\mathrm{i}}+\mathrm{c}_{\mathrm{i}}(\$ / \mathrm{h})$

The above function is constrained by below:

1. The generator bounds characterize the electrical inequality constraints in the economic dispatch formulation.

$$
\mathrm{P}_{\mathrm{i} \min } \leq \mathrm{P}_{\mathrm{i}} \leq \mathrm{P}_{\mathrm{i} \max } \quad \mathrm{i}=1, \ldots, \mathrm{n}
$$


2. Transmission losses affect the optimal economic scheduling of the generators .

Mathematically, the losses of power system can be represented in the form given by equations (2).

$$
\mathrm{P}_{\mathrm{L}}=\sum_{i=1}^{n} \sum_{\mathrm{j}=1}^{\mathrm{n}} \mathrm{P}_{\mathrm{i}} \mathrm{B}_{i j} \mathrm{P}_{\mathrm{j}}+\sum_{\mathrm{j}=1}^{\mathrm{n}} \mathrm{B}_{0 \mathrm{j}} \mathrm{P}_{\mathrm{j}}+\mathrm{B}_{00}
$$

The loss coefficients are calculated for different ranges of system load.

Equation (3) which represents the electrical equality constraints in the ED .

$\mathrm{P}_{\mathrm{D}}=\sum_{i=1}^{n} \mathrm{P}_{i}-\mathrm{P}_{\mathrm{L}}$

The objective function of the ED will be :

$\operatorname{minimize} \quad \mathrm{f}(\mathrm{FC})=\min \sum_{\mathrm{i}=1}^{\mathrm{n}} \mathrm{FC}_{\mathrm{i}}$

III. The proposed algorithm Whale Optimization Algorithm (WOA) [ 9,10,11,12]:

\subsection{Introduction}

The Whale Optimization Algorithm has been based on the hunting technique of baleen whale. This exceptional pursuing process is called bubble-net feeding strategy. Whales attempt to catch little fishes near the surface. It has been watched that this seeking is finished by a circle path as seemed in Figure. 1.

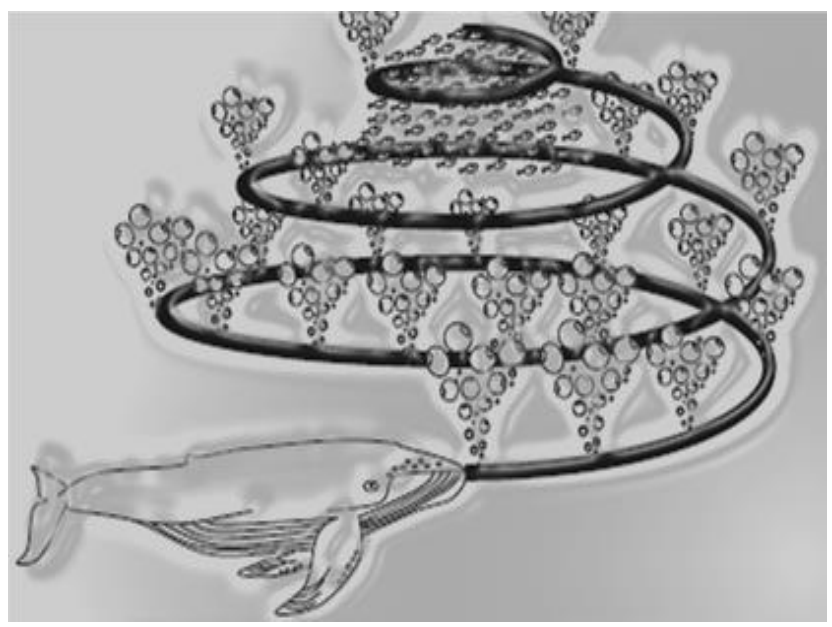

Figure.1 Bubble-net feeding technique of humpback whales

There are two actions related with above mentioned behavior named upward-spirals and twofold circles. In the first, whales dive around $12 \mathrm{~m}$ down and begin to make bubbles around the prey and swim toward the surface. The second includes three stages described fully in $[10,12]$. 


\subsection{Mathematical Description [11]}

Firstly, whales study the area of prey and circle them. The WOA tries to estimate present best candidate solution is the objective prey or is near the perfect. After the best search agent is defined, the other hunt operators will subsequently attempt to update their positions towards the best pursuit agent. This conduct is explained by equations below:

$$
\begin{aligned}
& D=\left|C . X^{*}(t)-X(t)\right| \ldots \ldots \ldots(5.1) \\
& X(t+1)=X^{*}(t)-A . D \ldots \ldots . .(5.2)
\end{aligned}
$$

where $\mathrm{t}$ demonstrates the present iteration, $\mathrm{A}$ and $\mathrm{C}$ are coefficient vectors, $\mathrm{X} *$ is the position vector of the best solution acquired as such, $X$ is the position vector, || is the absolute value and is a component by-component multiplication. It merits saying here that $\mathrm{X}^{*}$ should be updated in every iteration if there is a better solution. The vectors $\mathrm{A}$ and $\mathrm{C}$ are determined as below:

$$
\begin{aligned}
& \mathrm{A}=2 \mathrm{a} \cdot \mathrm{r}-\mathrm{a} \ldots \ldots . .(5.3) \\
& \mathrm{C}=2 \cdot \mathrm{r} \quad \ldots \ldots . .(5.4)
\end{aligned}
$$

where a is directly diminished from 2 to 0 through the span of emphases (in both investigation and exploitation stages) and $\mathrm{r}$ is an arbitrary vector in [0,1]. Eq. (5.2) permits any hunt operator to update its position in the area of the present best solution and recreates encompassing the prey.

\subsubsection{Bubble-net assaulting strategy (exploitation stage):}

Two strategies are utilized to figure the feeding conduct of humpback whales as follows:

\section{i. Shrinking circling system:}

This conduct is accomplished by decreasing the estimation of a in the Eq. (5.3). Note that the fluctuation scope of $\mathrm{A}$ is additionally diminished by a. As such $\mathrm{A}$ will be a random value in the interim [-a, a] where a is diminished from 2 to 0 throughout emphases. Setting A randomly in [ $-1,1]$, the new position of an inquiry operator can be characterized anyplace in the middle of the first position of the specialist and the position of the present best specialist. Figure. 2 (a) shows mathematically this behavior.

\section{ii. Spiral redesigning position:}

As can be found in Figure. 2 (b), this approach first determines the separation between the whale situated at $(\mathrm{X}, \mathrm{Y})$ and prey situated at $\left(\mathrm{X} *, \mathrm{Y}^{*}\right)$. A winding condition is then made between the position of whale and prey to mirror the helix-molded development of humpback whales as takes after:

$\mathrm{X}(\mathrm{t}+1)=\mathrm{D}^{\prime} \cdot \mathrm{e}^{\mathrm{bl}} \cdot \cos (2 \pi \mathrm{l})+\mathrm{X}^{*}(\mathrm{t})$

where $D^{\prime}=\left|X^{*}(t)-X(t)\right|$ and demonstrates the separation of the ith whale to the prey (best solution acquired in this way), $\mathrm{b}$ is a consistent for characterizing the state of the logarithmic winding, 1 is an random number in $[-1,1]$, and is a component by-component multiplication. Note that humpback whales swim around the prey inside a contracting circle and along a winding formed way all the while. To model this concurrent conduct, we accept that there is a probability of half to pick between either the contracting surrounding component or the winding model to overhaul the position of whales amid streamlining. The scientific model is as per the following: 


$$
\mathrm{X}^{*}(\mathrm{t})-\mathrm{A} . \mathrm{D} \quad \text { if } \mathrm{p}<0.5
$$

$X(t+1)=$

$$
D^{\prime} \cdot e^{b l} \cdot \cos (2 \pi l)+X^{*}(t) \quad \text { if } p \geq 0.5
$$

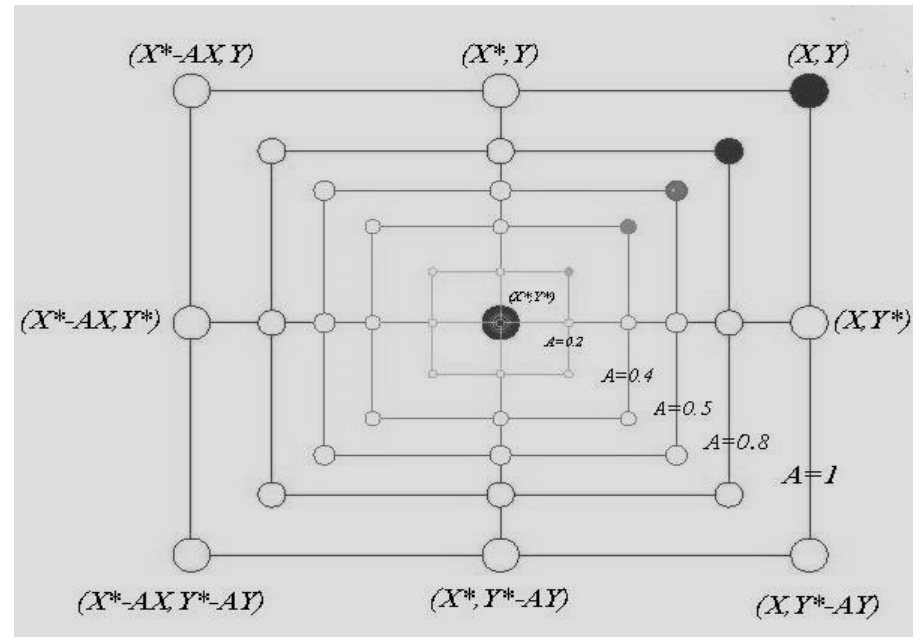

Figure. 2 (a) shrinking encircling mechanism updating position.

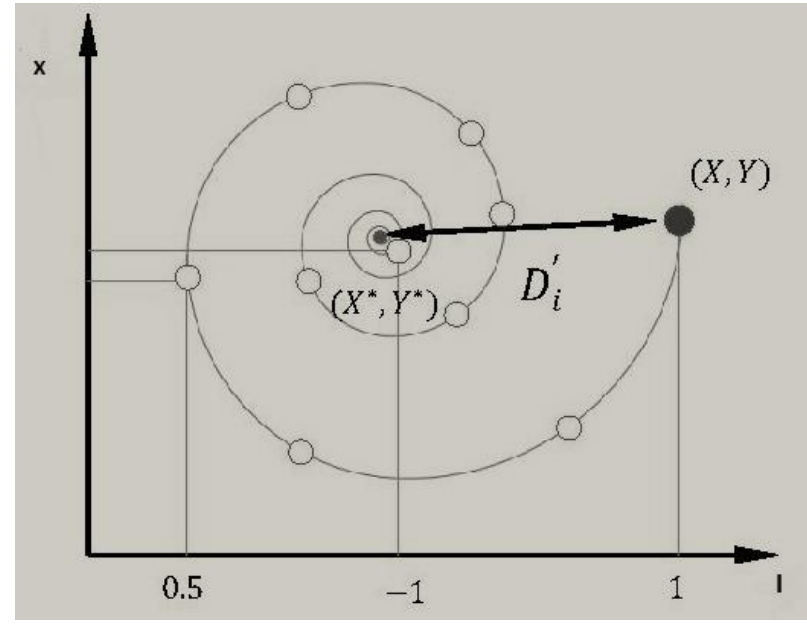

Figure. 2 (b) spiral

where $\mathrm{p}$ is an arbitrary number in $[0,1]$. Notwithstanding the bubble- net strategy, the humpback whales hunt prey randomly as in blow.

\subsubsection{Scan for prey (investigation stage)}

Definitely, humpback whales seek arbitrarily as per the position of each other. In this manner, A is utilized with the irregular qualities more than 1 or under -1 to make search agent to move far from a reference whale. Rather than the exploitation stage, the position of an inquiry operator has been updated in the investigation stage as per a randomly picked search agent rather than the best pursuit operator discovered in this way. This scheme and $|\mathrm{A}|>1$ highlight investigation and tolerate the WOA calculation to perform a global pursuit. The mathematical model is as per the following:

$\mathrm{D}=\left|\mathrm{C} \cdot \mathrm{X}_{\text {rand }}-\mathrm{X}\right|$

$\mathrm{X}(\mathrm{t}+1)=\mathrm{X}_{\text {rand }}-\mathrm{A} \cdot \mathrm{D}$

The WOA can be summarized in the below:

Step-1: Initialize the whales population $\mathrm{X}_{\mathrm{i}}(\mathrm{i}=1,2, \ldots, \mathrm{n})$

Step-2: Calculate the fitness of each search agent $\mathrm{X}^{*}=$ the best search agent

Step-3: for each search agent 
Update a, A, C, l, and $\mathrm{p} \quad$ (while $\mathrm{t}<$ maximum number of iterations)

Step-4: if1 $(\mathrm{p}<0.5)$ if $2|\mathrm{~A}|<1$

Step-5: Update the position of the current search agent by the Eq.(5.1)

Step-6: if 21 A $1 \geq 1$

Select a random search agent $\left(X_{\text {rand }}\right)$

Update the position of the current search agent by the Eq.(5.9)

Step-7 : if1 $(\mathrm{p} \geq 0.5)$

Update the position of the current search by the Eq. (5.5)

Step-8: if

Any search agent goes beyond the search space and amend it Calculate the fitness of each search update $\mathrm{X}^{*}$ if there is a better solution $\mathrm{t}=\mathrm{t}+1$

Step-9 : select new $\mathrm{X}^{*}$

\section{CASE STDUIED AND RESULTS}

The proposed approach has been implemented in this paper named WOA. The implementation is performed on standard test system of IEEE 30- Bus with 6 generator units ,41 transmission line and the load demand is $283.4 \mathrm{MW}$. The Matlab 7.8 version is used throughout this work on a laptop of Intel processor , CPU M 350@ 2.27 GHZ,RAM 4 GB(2.99G B usable, operating system 32 bit).

\subsection{IEEE 30-Bus Test System [6 , 8]}

The required data for this test system in Figure .3 are shown in tables 1 and 2.

Table 1 Fuel Cost Function Parameter

\begin{tabular}{|c|c|c|c|c|c|}
\hline \multirow{2}{*}{ Unit No. } & \multicolumn{3}{|c|}{ Fuel Cost Coefficients } & \multicolumn{2}{c|}{ Generation Limits } \\
\cline { 2 - 6 } & $\mathrm{a}\left(\$ / \mathrm{MW}^{2} \mathrm{~h}\right)$ & $\mathrm{b}(\$ / \mathrm{MWh})$ & $\mathrm{c}(\$ / \mathrm{h})$ & $\begin{array}{c}\text { Pmin } \\
(\mathrm{MW})\end{array}$ & $\begin{array}{c}\text { Pmax } \\
(\mathrm{MW})\end{array}$ \\
\hline 1 & 0.00375 & 2.00 & 0 & 50 & 200 \\
\hline 2 & 0.01750 & 1.75 & 0 & 20 & 80 \\
\hline 3 & 0.06250 & 1.00 & 0 & 15 & 50 \\
\hline 4 & 0.00834 & 3.25 & 0 & 10 & 35 \\
\hline 5 & 0.02500 & 3.00 & 0 & 10 & 30 \\
\hline 6 & 0.02500 & 3.00 & 0 & 12 & 40 \\
\hline
\end{tabular}


INTERNATIONAL JOURNAL OF ENGINEERING TECHNOLOGY AND SCIENCES (IJETS) Vol.5 (1)

June 2016 DOI: http://dx.doi.org/10.15282/ijets.5.2016.1.2.1041

Table 2 .B-coefficients

\begin{tabular}{|ccccccc|}
\hline $\mathrm{B}=$ \\
0.000218 & 0.000103 & 0.000009 & -0.00010 & 0.000002 & 0.000027 \\
0.000103 & 0.000181 & 0.000004 & -0.000015 & 0.000002 & 0.000030 \\
0.000009 & 0.000004 & 0.000417 & -0.000131 & -0.000153 & -0.000107 \\
-0.00010 & -0.000015 & -0.000131 & 0.000221 & 0.000094 & 0.000050 \\
0.000002 & 0.000002 & -0.000153 & 0.000094 & 0.000243 & -0.00000 \\
0.000027 & 0.000030 & -0.000107 & 0.000050 & -0.00000 & 0.000358 \\
& & & & & & \\
\hline $\mathrm{B} 00=-0.000003$ & 0.000021 & -0.000056 & 0.000034 & 0.000015 & 0.000078 \\
\hline $\mathrm{B} 0=0.000014$ & & & & & \\
\hline
\end{tabular}

Figure.3 IEEE 30- Bus Test System

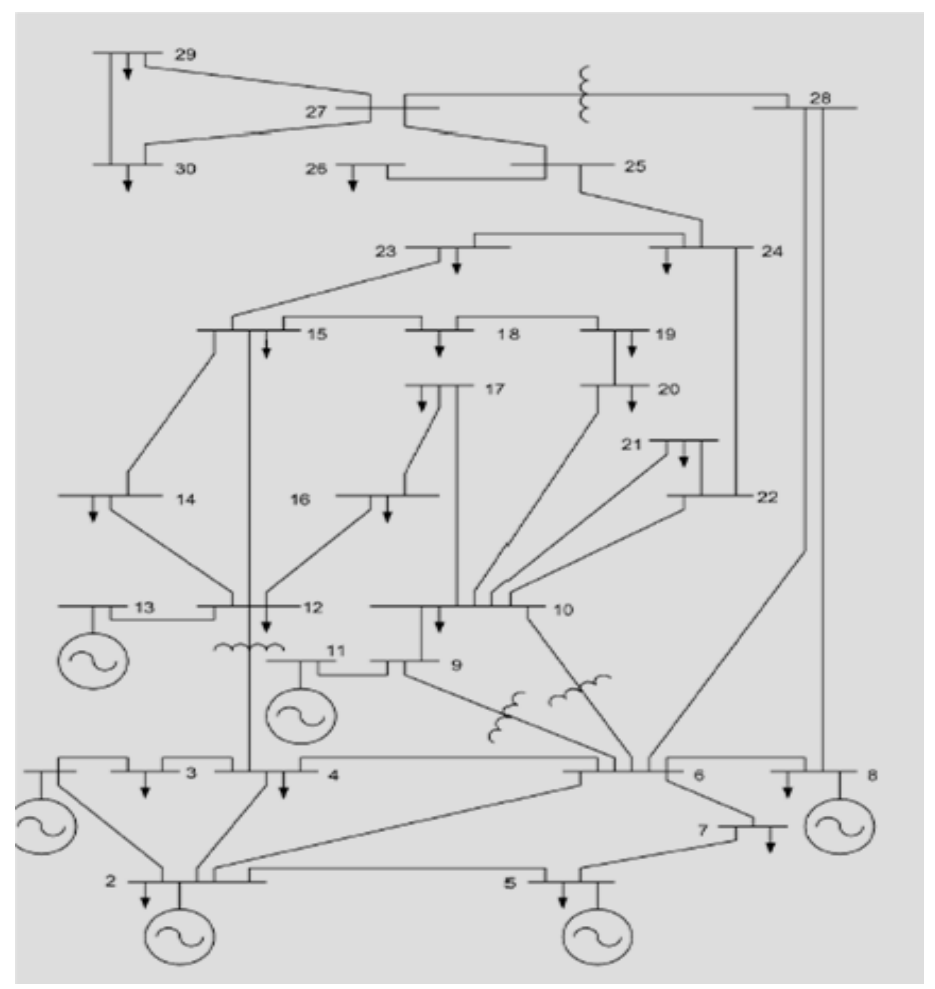


Tables 3 and 4 show a comparison results taken from $[13,14]$ and those obtained by new strategy WOA. The results illustrate a significant convergence in power outputs, total losses and total cost. The results of WOA are very competitive and reliable within a computation time is 1.601492 seconds by 100 iterations.

Table3. Power Output of six generators, IEEE 30- Bus (283.4 MW Demand Load).

\begin{tabular}{|c|c|c|c|c|c|c|}
\hline $\begin{array}{c}\text { Optimization } \\
\text { methods }\end{array}$ & P1 (MW) & P2 (MW) & P3 (MW) & P4 (MW) & P5 (MW) & P6 (MW) \\
\hline WOA & 174.4379 & 47.8294 & 21.4578 & 25.6931 & 10.1262 & 12.1515 \\
\hline PSO[13] & 176.94 & 48.71 & 21.27 & 21.09 & 11.83 & 12.00 \\
\hline GA[14] & 179.367 & 44.24 & 24.61 & 19.9 & 10.71 & 14.09 \\
\hline ACO[14] & 177.863 & 43.8366 & 20.893 & 23.1231 & 14.0255 & 13.1199 \\
\hline
\end{tabular}

Table 4.ED Results for IEEE 30- Bus (283.4 MW Demand Load)

\begin{tabular}{|c|c|c|}
\hline $\begin{array}{l}\text { Optimization } \\
\text { methods }\end{array}$ & PL (MW) & $\begin{array}{c}\text { Total Cost } \\
\text { (Fuel Cost) } \\
\$ / \mathrm{h}\end{array}$ \\
\hline WOA & 8.2972 & 800.2825 \\
\hline PSO[13] & 8.4382 & 798.43 \\
\hline GA[14] & 9.5177 & 803.699 \\
\hline ACO $[14]$ & 9.4616 & 803.123 \\
\hline
\end{tabular}

\section{Conclusion}

(WOA) has been utilized to determine the optimal solution for the ED problem. This algorithm has been tested on system of IEEE 30- Bus with six generating thermal units. A general conclusion can be indicated the proposed technique produced optimal or near optimal solutions. The obtained results for the certain test system explain and verify some facts such as the closeness between the (WOA) method and the mentioned techniques in the obtained results as it is proved in the case studied.

\section{Nomenclature}

$\mathrm{FC}_{\mathrm{i}} \quad$ fuel cost of unit (i) in $\$ / \mathrm{h}$.

$P_{i} \quad$ real power output of generator $i$.

a $\left(\$ / M^{2} h\right), b(\$ / M W h)$ and c $(\$ / h) \quad$ cost coefficients.

$\mathrm{n}$ number of units

$\mathrm{P}_{\mathrm{i} \text { min }}$ minimum limit for generating unit (i) in MW. 
INTERNATIONAL JOURNAL OF ENGINEERING TECHNOLOGY AND SCIENCES (IJETS) Vol.5 (1)

June 2016 DOI: http://dx.doi.org/10.15282/ijets.5.2016.1.2.1041

$\begin{array}{ll}\mathrm{P}_{\mathrm{i} \text { max }} & \text { maximum limit for generating unit (i) in } \mathrm{MW} . \\ \mathrm{P}_{\mathrm{L}} & \text { total losses in } \mathrm{MW} . \\ \mathrm{P}_{\mathrm{D}} & \text { total load demand in } \mathrm{MW} . \\ \mathrm{FC} & \text { total fuel cost }(\$ / \mathrm{h}) . \\ \mathrm{B} & \text { loss coefficients }\end{array}$

REFERENCES

[1] Allen J.Wood \& Bruce F. Wollen berg, "Power Generation, Operation and Control", John Wily \& Sons , Inc, USA; 1996.

[2] Girish Kumar, Rameshwar singh " "Economic Dispatch of Power System Optimization with Power Generation Schedule Using Evolutionary Technique", International Journal of Advanced Research in Electrical Electronics and Instrumentation Engineering; Vol. 3, Issue 7, July 2014.

[3] P.Ajay-D-Vimal Raj, et.al, "Optimal Power Flow Solution for Combined Economic Emission Dispatch Problem using Particle Swarm Optimization Technique" Journal of Electrical System JES ; (2007).

[4] BOMMIRANI.B, THENMALAR.K, "OPTIMIZATION TECHNIQUE FOR THE ECONOMIC DISPATCH IN POWER SYSTEM OPERATION ", International Journal of Computer and Information Technology (ISSN: 2279-0764); Volume 02- Issue 01, January 2013.

[5] Bishnu Sahu, Avipsa Lall, Soumya Das, T. Manoj Patra " Economic Load Dispatch in Power System using Genetic Algorithm" International Journal of Computer Applications (0975 - 8887); Volume 67- No.7, April 2013.

[6] Hadi Saadat “ Power System Analysis ”, by Mc Grew Hill. Inc ;1999.

[7] R Gnanadass, Narayana Prasad Padhy, et.al, "A New method for the Transmission Congestion Management in the Restructured Power Market", Faculty of Electrical Engineering Universiti Teknologi Malaysia ELEKTRIKA; VOL. 9, NO. 1, PP.52-58, 2007.

[8] Lahouari Abdelhakem Koridak ,et.al. "Hybrid Optimization of the Emission and Economic Dispatch by the Genetic Algorithm", Leonardo Journal of Sciences; Issue 14, January-June 2008.

[9] Watkins WA, Schevill WE . "Aerial observation of feeding behavior in four baleen whales: Eubalaena glacialis ,Balaenoptera borealis , Megapteranovaean-gliae, and Balaenopter physalus ", J Mammal; 1979:15563.

[10] Goldbogen JA, Friedlaender AS , Calambokidis J , Mckenna MF , Simon M , Nowacek DP "Integrative approaches to the study of baleen whale diving behavior, feeding performance, and foraging ecology ", BioScience ;2013;63:90-100 .

[11] Seyedali Mirjalili, Andrew Lewis, “ The Whale Optimization Algorithm”, School of Information and Communication Technology, Griffith University, Nathan Campus, Brisbane, QLD 4111, Australia b Griffith College, Mt Gravatt, Brisbane, QLD 4122, Australia ; (C2016 Elsevier Ltd. All rights reserved

[12] DavidWiley ${ }^{1,6)}$, Colin Ware ${ }^{2)}$, Alessandro Bocconcelli ${ }^{3)}$, Danielle Cholewiak ${ }^{1)}$, Ari Friedlaender ${ }^{4)}$, Michael Thompson") \& Mason Weinrich5), "Underwater components of humpback whale bubble-net feeding behavior", (C) Koninklijke Brill NV, Leiden; 2011.

.[13] Mohamed Abuella, Constantine J. Hatziadoniu, “ Selection of Most Effective Control Variables for Solving Optimal Power Flow Using Sensitivity Analysis in Particle Swarm Algorithm”, arXiv:1601.04150v1 [cs.CE] 16 Jan 2016

[14] SUREKHA P, Dr.S.SUMATHI , "Solving Economic Load Dispatch problems using Differential Evolution with Opposition Based Learning", WSEAS TRANSACTIONS on INFORMATION SCIENCE and APPLICATIONS ; Issue 1, Volume 9, January 2012 